\title{
Immunization and autism links: Ethics in research
}

\author{
Joanne Embree MD FRCPC
}

$\mathrm{I}^{\mathrm{n}}$ n 1998, the Lancet published a manuscript, written by Wakefield et al (1), that detailed 12 children who were referred to the gastroenterology clinic of the Royal Free Hospital and School of Medicine in London, United Kingdom, with what was described as chronic enterocolitis and regressive developmental disorder. Following a description of the extensive investigation of the cause of these children's medical illness, the authors hypothesized that the administration of the measles-mumps-rubella (MMR) vaccine could precipitate chronic inflammatory bowel disease that would then lead to autism. This hypothesis was announced to both the medical and scientific worlds and the general public via a press conference, at which time warnings were given that the combination MMR vaccine should not be given to young children because of the risk of development of this condition. Public and scientific controversy ensued. As a result, the number of children receiving measles immunization in the United Kingdom plummeted from a $92 \%$ to $95 \%$ before the announcement to estimates of $60 \%$ to $80 \%$ coverage depending upon the region and groups studied, and the extent of ongoing local press coverage of the story. The effect was felt elsewhere, including Canada, because pediatricians, family practitioners, public health nurses and other health care providers were questioned by worried parents about whether it was safe to have their children immunized with this vaccine. Whether immunization rates fell in Canada to the same extent as estimated in the United Kingdom is not known but, fortunately, is not thought to be likely. The debate triggered the allocation of significant amounts of funds targeted to conduct studies to confirm or refute the hypothesis, as well as formal investigations and scientific reviews by various expert panels (2-7). By 2001, the scientific and medical community had generally concluded that there was no evidence to support the hypothesis and had published recommendations that MMR immunization programs should be continued $(7,8)$. However, the issue continued to be debated in both the medical literature and the lay press resulting in a chronically poor uptake of measles and measles-containing vaccinations.

In February 2004, the results of a four-month investigation by reporters were announced in the British press related to concerns that, as a result of an undisclosed significant conflict of interest on the part of Dr Wakefield, the results published were questionable. The investigation has generated an accusation that Dr Wakefield had received a relatively large amount of money to find evidence of an association between receipt of immunization and the development of autism in a significant proportion of the children described in the manuscript, as part of legal action being taken by the parents of those children against the company that manufactured the MMR vaccine. The editor of the Lancet has indicated that, as a result of the investigation, the nondisclosure of this funding was of concern. Had the editors been aware of the funding issue at the time, it would have had affected their assessment of the data and conclusions drawn and would have affected the decision to publish the manuscript. Understandably, this has generated a call for a formal investigation of the circumstances surrounding the generation of the data and publication of the manuscript to answer the question, "How did this happen?" Some, if not all, of Dr Wakefield's collaborators have indicated that they were unaware of the contract and payment related to the legal cases. Fortunately, true science has actually prevailed. Dr Wakefield's hypothesis had not stood the tests of time, other scientists did not confirm his results. Some of his original collaborators had already begun to express doubt concerning the conclusions, and his hypothesis had generally been discounted before this story broke in the news.

The issue of disbelief of the published results of immunization studies because of alleged conflict of interest is not new. Opponents to vaccines and immunization programs have used these allegations for the past several years to discredit research results that support the safety and effectiveness of immunization. As a result, researchers who investigate the safety and efficacy of vaccines and official bodies that make recommendations related to immunization have become extremely careful to ensure that all potential or perceived conflicts of interest are openly declared so that the conclusions made can be evaluated appropriately. In situations where a true conflict of interest exists, the results may be assessed in making decisions but the opinions of the researchers are usually not sought. The same standards would be expected of any researcher, regardless of the expected results of their research. As such, Dr Wakefield had an obligation to disclose any financial arrangements or other conflicts of interest that could have influenced his interpretation of his findings. What should happen now? Obviously, an inquiry is in order. Millions of dollars have been spent and children's lives have likely been unnecessarily put at risk due to the consequences of measles as a direct result of the publicity associated with this Lancet paper. Would the same widespread consequences to measles immunization programs 
worldwide have occurred if there had been a disclosure that the study had been funded, in part, through an investigation to confirm a position taken in a legal action? Probably not.

There has been at least one positive aspect as a consequence to all of this controversy. The problems related to the diagnosis and treatment of autism has gained international attention. Determining the cause of autism has become a priority. How unfortunate it is that the money spent trying to determine whether MMR caused autism had not been spent studying more productive avenues of research.

Recently, another manuscript detailing the results of research concerning the cause of autism has generated extensive press coverage in Canada, partly because of the reputation of the universities with which the authors were associated. In conversations with the press, relating to the well publicized, advanced on line publication of the manuscript in Molecular Psychiatry (9), Dr Deth's comments reflected his belief that his

\section{REFERENCES}

1. Wakefield AJ, Murch SH, Anthony A, et al. Ileal-lymphoidnodular hyperplasia, non-specific colitis, and pervasive developmental disorder in children. Lancet 1998;351:637-41.

2. Taylor B, Miller E, Farrington CP, et al. Autism and measles, mumps, and rubella vaccine: No epidemiological evidence for a causal association. Lancet 1999;353:2026-9.

3. Kaye JA, del Mar Melero-Montes M, Jick H. Mumps, measles, and rubella vaccine and the incidence of autism recorded by general practitioners: A time trend analysis. BMJ 2001;322:460-3.

4. Dales L, Hammer SJ, Smith NJ. Time trends in autism and in MMR immunization coverage in California. JAMA 2001;285:1183-5.

5. Taylor B, Miller E, Lingham R, Andrews N, Simmons A, Stowe J. Measles, mumps, and rubella vaccination and bowel problems or developmental regression in children with autism: Population study. BMJ 2002;324:393-6. results were supportive of the argument that thimerosal in vaccines causes autism (9). Questions were immediately raised by the press and public about the safety of the influenza vaccines provided for children in Canada, because they contain thimerosal in small amounts. The manuscript describes a very complex study involving many basic science experiments using neurological cancer cell lines. Generalization of these laboratory results as an explanation of events in the human central nervous system of a child is tenuous at best. They are not sufficient to support the statements made related to thimerosal as the cause of autism. In reviewing the manuscript, I am unable to determine how the study was funded. In view of the controversy surrounding the previous Lancet publication, authors and publishers would be well advised to ensure that relevant information concerning the sources of funding and potential conflicts of interest are published in association with the results of their studies.

6. Fombonne E, Chakrabarti S. No evidence for a new variant of measles-mumps-rubella-induced autism. Pediatrics 2001;108:E58.

7. Halsey NA, Hyman SL; Conference Writing Panel. Measlesmumps-rubella vaccine and autistic spectrum disorder: Report from the New Challenges in Childhood Immunizations Conference convened in Oak Brook, Illinois, June 12-13, 2000. Pediatrics 2001;107:E84.

8. Infectious Diseases and Immunization Committee, The Canadian Pediatric Society. Measles-mumps-rubella vaccine and autistic spectrum disorder: A hypothesis only. Paediatr Child Health 2001;6:387-9.

9. Waly M, Olteanu H, Banerjee R, et al. Activation of methionine synthase by insulin-like growth factor-1 and dopamine: A target for neurodevelopmental toxins and thimerosal. Mol Psychiatry 2004;9:358-70. 


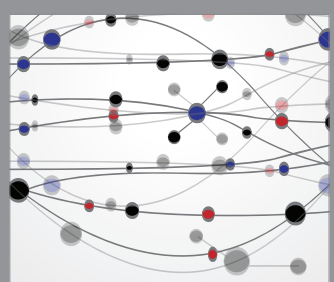

The Scientific World Journal
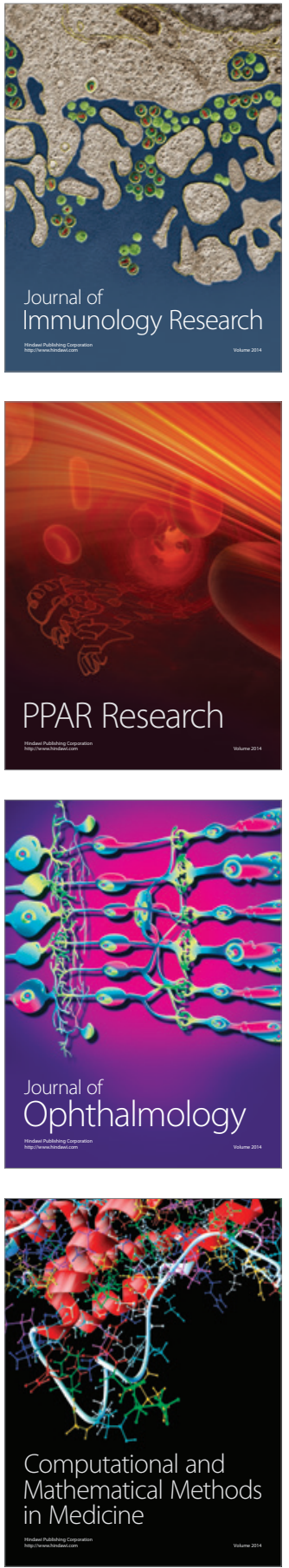

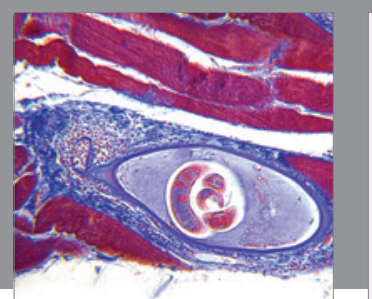

Gastroenterology Research and Practice

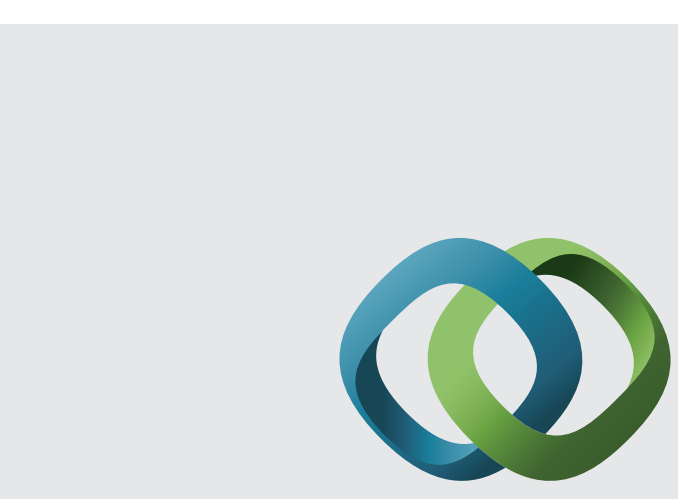

\section{Hindawi}

Submit your manuscripts at

http://www.hindawi.com
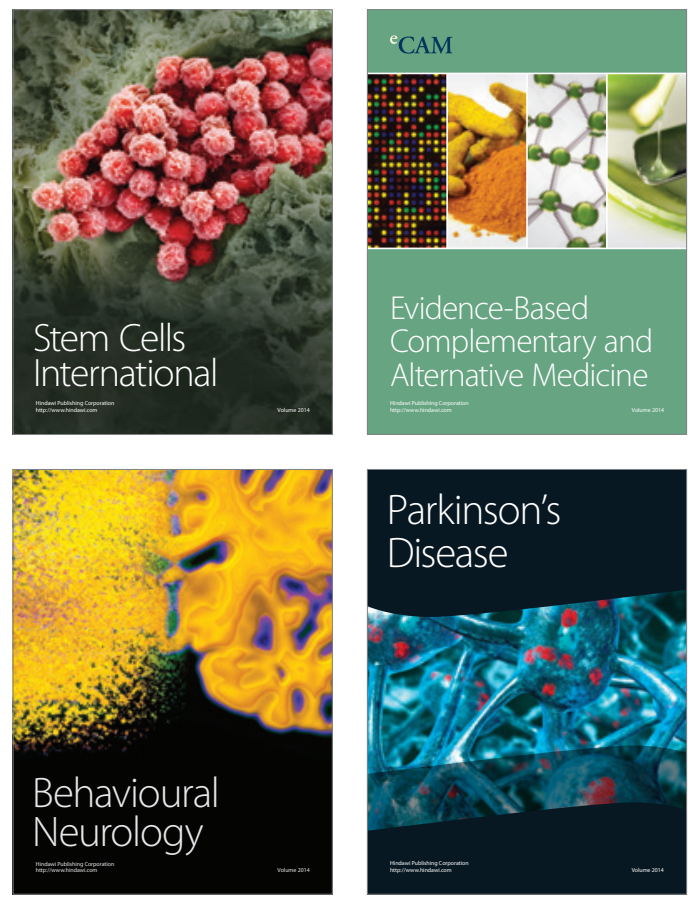
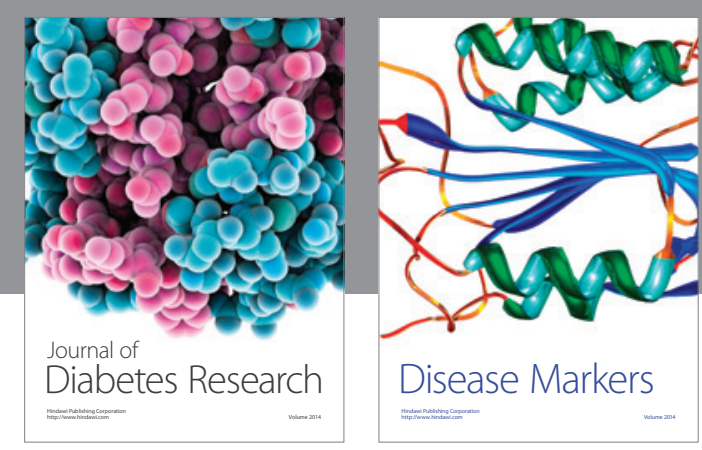

Disease Markers
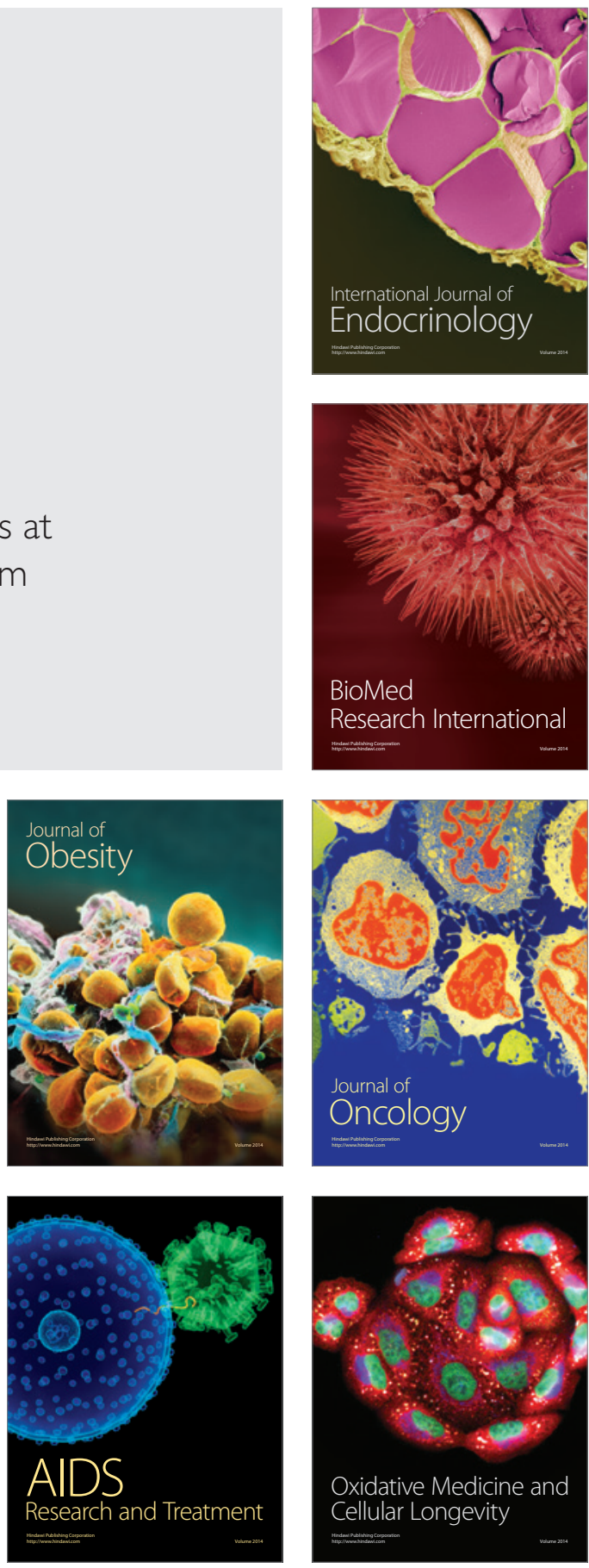